\title{
Genetic Diversity of Pseudomonas syringae pv. actinidiae Strains from Different Geographic Regions in China
}

\author{
Rong He, ${ }^{1}$ Pu Liu, ${ }^{1}$ Bing Jia, ${ }^{1}$ Shizhou Xue, ${ }^{1}$ Xiaojie Wang, ${ }^{1}$ Jiayong Hu, ${ }^{1}$ Yosef Al Shoffe, ${ }^{2}$ \\ Lorenzo Gallipoli, ${ }^{3}$ Angelo Mazzaglia, ${ }^{3}$ Giorgio M. Balestra, ${ }^{3}$ and Liwu Zhu ${ }^{1,2, \dagger}$
}

${ }^{1}$ Key Lab of Pomology, School of Horticulture, Anhui Agricultural University, West Changjiang Road 130, Hefei 230036, Anhui Province, P.R. China; ${ }^{2}$ Section of Horticulture, College of Agriculture and Life Sciences, Cornell University, Ithaca, NY 14853, USA; and ${ }^{3}$ Department of Science and Technologies for Agriculture, Forestry, Nature and Energy, University of Tuscia, Via S. Camillo de Lellis 01100, Viterbo, Italy Accepted for publication 15 September 2018.

\begin{abstract}
Pseudomonas syringae pv. actinidiae causes kiwifruit bacterial canker, with severe infection of the kiwifruit plant resulting in heavy economic losses. Little is known regarding the biodiversity and genetic variation of populations of $P$. syringae pv. actinidiae in China. A collection of 269 strains of $P$. syringae pv. actinidiae was identified from 300 isolates obtained from eight sampling sites in five provinces in China. The profiles of 50 strains of $P$. syringae pv. actinidiae and one strain of $P$. syringae pv. actinidifoliorum were characterized by Rep-, insertion sequences 50 , and randomly amplified polymorphic DNA polymerase chain reaction (PCR). Discriminant analysis of principal coordinates, principal component analysis, and hierarchical cluster analysis were used to analyze the combined fingerprints of the different PCR assays. The results revealed that all isolates belonged to the Psa3 group, that strains of $P$. syringae pv. actinidiae from China have broad genetic variability that was related to source geographic region, and that Chinese strains can be readily differentiated from strains from France

but are very similar to those from Italy. Multilocus sequence typing of 24 representative isolates using the concatenated sequences of five housekeeping genes (cts, gapA, gyrB, pfk, and $r p o D$ ) demonstrated that strain Jzhy2 from China formed an independent clade compared with the other biovars, which possessed the hopHl effector gene but lacked the hopAl effector gene. A constellation analysis based on the presence or absence of the four loci coding for phytotoxins and a cluster analysis based on the 11 effector genes showed that strains from China formed two distinct clades. All of the strains, including K3 isolated in 1997 from Jeju, Korea, lacked the $c f l$ gene coding for coronatine. In contrast, the $\operatorname{tox}-\arg K$ gene cluster coding for phaseolotoxin was detected in $\mathrm{K} 3$ and in the biovar 1 strains (K3, Kw30, and Psa92), and produced a falsepositive amplicon for the hopAM1-like gene in this study. To date, only one biovar (biovar 3 ) is represented by the strains of $P$. syringae pv. actinidiae from China, despite China being the center of origin for kiwifruit.
\end{abstract}

Kiwifruit (Actinidia chinensis Planchon and A. deliciosa Liang et Ferguson) is an important fruit crop, with primary production in China, Italy, and New Zealand (Vanneste 2017). Pseudomonas syringae pv. actinidiae is the causal agent of kiwifruit bacterial canker (KBC) and was first discovered in Japan in the early 1980s (Takikawa et al. 1989). There were earlier reports of a similar disease in California, United States (Opgenorth et al. 1983), but the causal bacterium was demonstrated to be different from that subsequently characterized in Japan (Takikawa et al. 1989). Within 10 years of identifying $P$. syringae pv. actinidiae, serious economic losses due to the disease were reported from South Korea (Koh et al. 1994). P. syringae pv. actinidiae was reported infecting kiwifruit in Italy and in China, where KBC was first reported in Hunan Province in 1985 and later reported in Anhui and Sichuan Provinces. Although the outbreak of KBC on A. deliciosa 'Qinmei' in Shaanxi

${ }^{\dagger}$ Corresponding author: Liwu Zhu;

E-mail: zhuliwu@ahau.edu.cn; 1z535@cornell.edu

Funding: This project was supported by the National Natural Science Foundation of China (31401831), Anhui Provincial Annual Key Project Foundation (1804a07020105), Anhui Provincial Natural Science Foundation (1408085QC62), Discipline Capacity Promotion at Anhui Agricultural University, China (XKTS 2013010), and Foreign Visiting Scholars of Anhui Higher Education Revitalization (gxfxZD2016023)

R. He and P. Liu contributed equally to this work.

*The $\boldsymbol{e}$-Xtra logo stands for "electronic extra" and indicates that three supplementary figures and three supplementary tables are published online.

(c) 2019 The American Phytopathological Society
Province was first observed in 1991, it was not reported until 10 years later (Liang et al. 2000).

Despite a lack of prior knowledge concerning the target DNA sequences, polymerase chain reaction (PCR) amplification of the enterobacterial repetitive intergenic consensus (ERIC) sequences, Box elements (BOX, or repetitive sequence elements) and (GTG)5 elements in bacterial genomes (collectively called Rep-PCR), randomly amplified polymorphic DNA (RAPD)-PCR, and insertion sequences 50 (IS50)-PCR are highly discriminating approaches for characterizing genetic relationships between strains and pathovars of Pseudomonas spp. (Weingart and Volksch 1997). The combination of Rep-PCR and IS50-PCR was previously demonstrated to provide high resolution genomic fingerprinting to discern intrapathovar diversity among strains of $P$. syringae pv. actinidiae (Mazzaglia et al. 2011).

There are four groups of $P$. syringae pv. actinidiae strains (Psa1 to -4) proposed based on multilocus sequence typing (MLST): Psa1 represents isolates from Japan and Italy; Psa2 represents isolates from Korea; Psa3 represents isolates from Italy, New Zealand, Chile, and China; and Psa4 represents isolates from New Zealand and Australia that exhibit low virulence (EPPO 2011). Moreover, four subpathovars or biovars (biovars 1 to 4 ) of $P$. syringae pv. actinidiae have been discriminated and named based on molecular characteristics, BOX-PCR electrophoretic profiles, the presence of type III secretion system effector protein genes (effector genes) hopAl and $a v r D$, and virulence differences observed in the field. $P$. syringae pv. actinidiae strains in biovar 3 (found in Italy since 2008 and in New Zealand, Chile, and China) and biovar 4 (New Zealand) are separated from those isolated from past epidemics in Japan and Italy (biovar 1) or Korea (biovar 2) (Vanneste et al. 2013). 
Strains belonging to biovar 4 have been described as a new pathovar; namely, $P$. syringae pv. actinidifoliorum pv. nov. (Cunty et al. 2015b).

Although there have been several reports describing the occurrence of $\mathrm{KBC}$ in different provinces of China (Liang et al. 2000), the collection of strains of $P$. syringae pv. actinidiae from China is quite limited. Thus, the genetic diversity of populations of $P$. syringae pv. actinidiae from different geographic regions in China has not been characterized. However, recent availability of strains from China with associated genetic marker studies (Ciarroni et al. 2015; Cunty et al. 2015a) and the sequence of the genomes of $P$. syringae pv. actinidiae have provided some insight into the population biology and epidemiology of this important disease (Andersen et al. 2018; McCann et al. 2017), which is valuable in understanding how climate change may affect distribution of P. syringae pv. actinidiae in the future (Wang et al. 2018).

To gather more information on the genetic diversity of populations of $P$. syringae pv. actinidiae from different geographic regions in China, we collected 296 strains of $P$. syringae pv. actinidiae from 2012 to 2014. Of these strains, 51 (including $P$. syringae pv. actinidifoliorum strain 18804) were selected to study diversity and variation using Rep-, RAPD-, and IS50-PCR. Furthermore, five housekeeping genes (cts, gapA, gyrB, pfk, and rpoD) of 24 representative $P$. syringae pv. actinidiae strains were sequenced, and four loci for the coronatine or phaseolotoxin biosynthesis pathway and 11 effector protein genes were cloned and used to elucidate the phylogenetic relationships among strains of $P$. syringae pv. actinidiae worldwide.

\section{MATERIALS AND METHODS}

Collection of $\boldsymbol{P}$. syringae pv. actinidiae strains. A collection of 269 strains of $P$. syringae pv. actinidiae was identified from 300 isolates obtained from eight sampling sites in five different kiwifruit-producing regions of China: Jiading District, in Shanghai municipality along the East Sea coastline; Yuexi and Jinzhai Counties in the Dabie mountain area of Anhui Province; Xiuwen County, in the southwest mountain area of Guizhou Province; Mianzhu and Pengzhou County, in the southwest basin of Sichuan Province; and Huxian and Weixian Counties, in the northwest plain of Shaanxi Province in China (Supplementary Fig. S1).

These strains were isolated from diseased leaves or branches of kiwifruit and from three nonkiwifruit species (Paulownia tomentosa, Setaira viridis, and Alternanthera philoxeroides) and two species of leafhoppers (Nephotettix bipunctatus (Fabricius) and Philagra hexamaculata Schmidt) (Table 1). Samples collected from diseased plant tissue were cut with a sterile blade and suspended in sterile distilled water. The suspensions were diluted, streaked on nutrient-sucrose agar, and incubated at $28^{\circ} \mathrm{C}$ for 24 to $48 \mathrm{~h}$ in the dark (Mazzaglia et al. 2011). Pure cultures were obtained by transferring a single colony to King's B medium at 25 to $28^{\circ} \mathrm{C}$ for 10 to $12 \mathrm{~h}$ in the dark. The preliminary identification of all isolates was performed according to standard bacteriological techniques (Takikawa et al. 1989). Molecular confirmation was by PCR amplification of two sets of primers specific to Pseudomonas syringae pv. actinidiae using genomic DNA (gDNA), as described by Koh and Nou (2002) and Rees-George et al. (2010).

Biochemical characterization of isolates. The ability of the bacterial strain to induce a hypersensitive reaction (HR) when injected into tobacco plants was tested, as was the ability to rot potato, both following described protocols (Vanneste et al. 2013). Ice nucleation activity was determined as described by Lindow et al. (1978). The production of syringomycin was determined according to Gross and DeVay (1977). The absence of cytochrome C oxidase, a characteristic that differentiates $P$. syringae from other species of plant-pathogenic fluorescent Pseudomonas spp., was determined using Test Oxidase (Pro-Lab Diagnostics Inc., Round Rock, TX, USA). Production of levan and an arginine dihydrolase under anaerobic conditions and the ability to hydrolyze esculin were determined using a previously described method (Lelliot et al. 1966).

Selection of additional strains and pathovars of $\boldsymbol{P}$. syringae pv. actinidiae. In all, 51 strains of $P$. syringae pv. actinidiae from different geographic regions and 3 other pathovars of Pseudomonas spp. were used to determine phylogenetic relationships (Table 1). Of these strains, 37 were selected from the collection of 296 strains of $P$. syringae pv. actinidiae collected in China: 3 to 5 representative strains were selected from different sampling sites by the prereaction of different PCRs with the criteria of pattern similarity. A further 14 strains of $P$. syringae pv. actinidiae were selected from Italy (five strains), Spain (2 strains), France (2 strains), Portugal (1 strain), New Zealand (2 strains), Korea (1 strain), and Japan (1 strain). In addition, 25 characterized strains from New Zealand, Italy, Chile, Australia, Korea, Japan, and the United States previously deposited in the National Center for Biotechnology Information (NCBI) database were used to analyze the nucleotide sequences of the different housekeeping genes (Supplementary Table S1).

gDNA extraction. Bacterial Genomic DNA Isolation Kits (Norgen Biotek Corp., Thorold, ON, Canada) were used to obtain gDNA from freshly grown cultures of each strain. The quality of gDNA of each strain was checked using a Beckman-Coulter DU800 UVVisible spectrophotometer (Beckman Coulter, Inc., Pasadena, CA, USA). The DNA concentration was adjusted to $50 \mathrm{ng} / \mu \mathrm{l}$ with TrisEDTA buffer (Tris- $\mathrm{HCl}$ and EDTA, $\mathrm{pH} \mathrm{8.0)}$ ) and stored at $-80^{\circ} \mathrm{C}$.

Different PCR assays. Primers were selected for Rep-, IS50-, and RAPD-PCR assays and were synthesized by Sengon Co., Ltd. (Shanghai, P.R. China) (Table 2). All 296 isolates of P. syringae pv. actinidiae were screened against all primers. Three repetitive sequences primer sets-ERIC1R-ERIC2, BOXA1R, and (GTG) 5-were chosen for the Rep-PCR amplification (Mazzaglia et al. 2011). In addition, Primer IS50 complementary to the insertion sequence IS50 of Tn5 was used for strain typing. The Rep-PCR and IS50-PCR reactions were performed in a final volume of $25 \mu \mathrm{l}$ containing $12.5 \mu \mathrm{l}$ of $2 \times$ Taq PCR MasterMix (Aidlab Biotechnologies Co., Ltd., Beijing, China), $1 \mu$ l of template DNA, $1 \mu$ l of each primer $(10 \mathrm{nmol} / \mu \mathrm{l})$, and $10.5 \mu \mathrm{l}$ of sterile distilled water. The RepPCR amplification was performed at $95^{\circ} \mathrm{C}$ for $7 \mathrm{~min}$; followed by 30 cycles of a denaturation step of $94^{\circ} \mathrm{C}$ for $60 \mathrm{~s}$, the annealing temperature of each primer for $60 \mathrm{~s}$, and extension at $72^{\circ} \mathrm{C}$ for $8 \mathrm{~min}$; and a final extension step at $72^{\circ} \mathrm{C}$ for $15 \mathrm{~min}$. The IS50-PCR amplification conditions were as follows: an initial denaturation cycle of $95^{\circ} \mathrm{C}$ for $7 \mathrm{~min} ; 40$ cycles of denaturation at $94^{\circ} \mathrm{C}$ for $1 \mathrm{~min}$, annealing at $45^{\circ} \mathrm{C}$ for $1 \mathrm{~min}$, and extension at $72^{\circ} \mathrm{C}$ for $5 \mathrm{~min}$; and a final extension step of $72^{\circ} \mathrm{C}$ for $15 \mathrm{~min}$.

Eight primers with arbitrary nucleotide sequences were selected from a panel of 160 RAPD primers screened to produce clear, reliable, and discriminable RAPD profiles; strains of $P$. syringae $\mathrm{pv}$. actinidiae and $P$. syringae were tested according to previous protocols (Lee et al. 2005). Amplification was performed in a total volume of $20 \mu \mathrm{l}$ containing $1 \mu \mathrm{l}$ of each primer, $1 \mu \mathrm{l}$ of the template DNA, $10 \mu \mathrm{l}$ of $2 \times$ Taq PCR MasterMix, and $7 \mu \mathrm{l}$ of sterile distilled water. The amplification consisted of an initial denaturation step of $95^{\circ} \mathrm{C}$ for $5 \mathrm{~min}$; followed by 40 cycles of $94^{\circ} \mathrm{C}$ for $60 \mathrm{~s}$, the annealing temperature of each primer for $60 \mathrm{~s}$, and $72^{\circ} \mathrm{C}$ for $5 \mathrm{~min}$; and a final extension step of $72^{\circ} \mathrm{C}$ for $15 \mathrm{~min}$.

Amplification products $(8 \mu \mathrm{l})$ were separated on a $1 \%$ agarose gel in $1 \times$ Tris-borate-EDTA buffer. All PCR amplifications were repeated twice to ensure reproducibility.

DNA fingerprints of the strains were visually inspected for similarity and were considered identical if the scored bands were at the same apparent migration distance, without consideration of variation in amplicon intensity. Amplified fragments of each strain were scored as 1 if present in all three runs but 0 if absent, even if absent in only one experimental run, which demonstrated that the fragment was not amplified reliably. The resulting matrix of 0 and 1 
data representing amplicons from strains by primers using the Rep-, IS50-, and RAPD-PCR assays was subject to analysis. Discriminant analysis of principal coordinates (DAPC) (Jombart et al. 2010) was conducted according to the Wide Linear model, principal components analysis (PCA) was performed using covariances, and strain differences between countries for each principal component (PC) were explored based on least square means, Hierarchical cluster analysis was performed using the Ward method, and one-way analysis of variance (ANOVA) of PCs was performed with means separation using Duncan's new multiple-range method $(\alpha=0.05)$. Analyses were calculated using the software JMP for Windows (version Pro 14; SAS, Cary, NC, USA).
MLST of the housekeeping gene. To identify the biovar (MLST group) of the strains of $P$. syringae pv. actinidiae from the population in China, five housekeeping genes-cts (gltA), gapA, gyrB, pfk, and rpoD-that code for citrate synthase, glyceraldehyde-3-phosphate dehydrogenase, DNA gyrase B, phosphofructokinase, and $\sigma$ factor 70 , respectively, were cloned using a previously described method (Sarkar and Guttman 2004). The MLST was performed on 24 strains selected from each clade of the dendrogram based on the combined data of the 51 strains of P. syringae pv. actinidiae characterized using different PCR assays described in the previous section. Sequencing of the housekeeping genes was performed using the CEQ-DTCS Quick Start kit (Beckman Coulter, Inc.) on a Beckman-Coulter CEQ 8000 DNA

TABLE 1. Bacterial strains used in this study showing source, species or pathovar, geographic origin, year, and host from which they were isolated

\begin{tabular}{|c|c|c|c|c|c|c|c|c|c|}
\hline Number & Strain name & Source & Sp. ${ }^{a}$ & $\begin{array}{l}\text { Host species, } \\
\text { cultivar }\end{array}$ & Tissue $^{b}$ & Year $^{\mathrm{c}}$ & $\begin{array}{c}\text { Geographic } \\
\text { origins }\end{array}$ & Orchard name & Collection $^{\mathrm{d}}$ \\
\hline 1 & Schy3 & AHAU, China & Psa & Actinidia chinensis 'Hongyang' & Vine & 2013 & Penzhou, Sichuan, China & Agri-Bumper & This study \\
\hline 2 & Schy4 & AHAU, China & Psa & A. chinensis 'Hongyang' & Vine & 2013 & Penzhou, Sichuan, China & Agri-Bumper & This study \\
\hline 3 & Schy5 & AHAU, China & Psa & A. chinensis 'Hongyang' & Vine & 2013 & Penzhou, Sichuan, China & Agri-Bumper & This study \\
\hline 4 & Schy9 & AHAU, China & Psa & A. chinensis 'Hongyang' & Vine & 2013 & Penzhou, Sichuan, China & Agri-Bumper & This study \\
\hline 5 & Scht12 & AHAU, China & Psa & A. chinensis 'Hongyang' & Vine & 2013 & Penzhou, Sichuan, China & Agri-Bumper & This study \\
\hline 6 & $\mathrm{SH} 2$ & AHAU, China & Psa & A. chinensis 'Hongyang' & Leaf & 2013 & Jiading, Shanghai, China & Agri-Tech & This study \\
\hline 7 & SH8 & AHAU, China & Psa & A. chinensis 'Hongyang' & Leaf & 2013 & Jiading, Shanghai, China & Agri-Tech & This study \\
\hline 8 & SH13 & AHAU, China & Psa & A. chinensis 'Hongyang' & Leaf & 2013 & Jiading, Shanghai, China & Agri-Tech & This study \\
\hline 9 & SH18 & AHAU, China & Psa & A. chinensis 'Hongyang' & Leaf & 2013 & Jiading, Shanghai, China & Agri-Tech & This study \\
\hline 10 & $\mathrm{SH} 26$ & AHAU, China & Psa & A. chinensis 'Hongyang' & Leaf & 2013 & Jiading, Shanghai, China & Agri-Tech & This study \\
\hline 11 & GC31 & AHAU, China & Psa & A. deliciosa 'Guichang' & Vine & 2012 & Xiuwen, Guizhou, China & Wangjiapu & This study \\
\hline 12 & GC32 & AHAU, China & Psa & A. deliciosa 'Guichang' & Vine & 2012 & Xiuwen, Guizhou, China & Wangjiapu & This study \\
\hline 13 & GC40 & AHAU, China & Psa & A. deliciosa 'Guichang' & Leaf & 2012 & Xiuwen, Guizhou, China & Wangjiapu & This study \\
\hline 14 & GC41 & AHAU, China & Psa & A. deliciosa 'Guichang' & Leaf & 2012 & Xiuwen, Guizhou, China & Wangjiapu & This study \\
\hline 15 & GC42 & AHAU, China & Psa & A. deliciosa 'Guichang' & Leaf & 2012 & Xiuwen, Guizhou, China & Wangjiapu & This study \\
\hline 16 & WT2 & AHAU, China & Psa & Paulownia tomentosa & Leaf & 2013 & Yuexi, Anhui, China & Zhubozhen & This study \\
\hline 17 & WT3 & AHAU, China & Psa & P. tomentosa & Leaf & 2013 & Yuexi, Anhui, China & Zhubozhen & This study \\
\hline 18 & $\mathrm{P} 1$ & AHAU, China & Psa & Philagra hexamaculata & Spume & 2013 & Yuexi, Anhui, China & Zhubozhen & This study \\
\hline 19 & $\mathrm{P} 2$ & AHAU, China & Psa & P. hexamaculata & Spume & 2013 & Yuexi, Anhui, China & Zhubozhen & This study \\
\hline 20 & P3 & AHAU, China & Psa & P. hexamaculata & Spume & 2013 & Yuexi, Anhui, China & Zhubozhen & This study \\
\hline 21 & INS & AHAU, China & Psa & Bothrogonia ferruginea & Body & 2012 & Yuexi, Anhui, China & Zhubozhen & This study \\
\hline 22 & JF8 & AHAU, China & Psa & A. chinensis 'Jinfeng' & Leaf & 2012 & Yuexi, Anhui, China & Zhubozhen & This study \\
\hline 23 & $\mathrm{JF} 27$ & AHAU, China & Psa & A. chinensis 'Jinfeng' & Leaf & 2012 & Yuexi, Anhui, China & Zhubozhen & This study \\
\hline 24 & Hwd1 & AHAU, China & Psa & A. deliciosa 'Hayward' & Leaf & 2012 & Huxian, Shaanxi, China & Baixiaqu & This study \\
\hline 25 & Hwd3 & AHAU, China & Psa & A. deliciosa 'Hayward' & Leaf & 2012 & Huxian, Shaanxi, China & Baixiaqu & This study \\
\hline 26 & Hwd4 & AHAU, China & Psa & A. deliciosa 'Hayward' & Leaf & 2012 & Huxian, Shaanxi, China & Baixiaqu & This study \\
\hline 27 & Hwd5 & AHAU, China & Psa & A. deliciosa 'Hayward' & Leaf & 2012 & Huxian, Shaanxi, China & Baixiaqu & This study \\
\hline 28 & Hwd6 & AHAU, China & Psa & A. deliciosa 'Hayward' & Leaf & 2012 & Huxian, Shaanxi, China & Baixiaqu & This study \\
\hline 29 & Jzhy2 & AHAU, China & Psa & A. chinensis 'Hongyang' & Leaf & 2013 & Jinzhai, Anhui, China & Tanghui & This study \\
\hline 30 & Jzhy3 & AHAU, China & Psa & A. chinensis 'Hongyang' & Leaf & 2013 & Jinzhai, Anhui, China & Tanghui & This study \\
\hline 31 & Jzhy6 & AHAU, China & Psa & A. chinensis 'Hongyang' & Leaf & 2013 & Jinzhai, Anhui, China & Tanghui & This study \\
\hline 32 & Jzzm1 & AHAU, China & Psa & A. chinensis wild seedlings & Leaf & 2013 & Jinzhai, Anhui, China & Tanghui & This study \\
\hline 33 & Jzzm2 & AHAU, China & Psa & A. chinensis wild seedlings & Leaf & 2013 & Jinzhai, Anhui, China & Tanghui & This study \\
\hline 34 & Jzmc1 & AHAU, China & Psa & Setaira viridis & Leaf & 2013 & Jinzhai, Anhui, China & Tanghui & This study \\
\hline 35 & Jzmc2 & AHAU, China & Psa & S. viridis & Leaf & 2013 & Jinzhai, Anhui, China & Tanghui & This study \\
\hline 36 & Jzgmc1 & AHAU, China & Psa & Alternanthera philoxeroides & Leaf & 2013 & Jinzhai, Anhui, China & Tanghui & This study \\
\hline 37 & Jzgmc2 & AHAU, China & Psa & A. philoxeroides & Leaf & 2013 & Jinzhai, Anhui, China & Tanghui & This study \\
\hline 38 & 7285 & CFBP & Psa & Actinidia chinensis 'Jintao' & Leaf & 2008 & Veneto, Italy & $\ldots$ & DAFNE, UT \\
\hline 39 & 7286 & CFBP & Psa & A. chinensis 'Hort16A' & Leaf & 2008 & Latina, Italy & $\ldots$ & DAFNE, UT \\
\hline 40 & LT19 & Balestra & Psa & A. deliciosa 'Hayward' & Leaf & 2008 & Latina, Italy & $\ldots$ & DAFNE, UT \\
\hline 41 & LT80 & Balestra & Psa & A. deliciosa 'Hayward' & Vine & 2008 & Latina, Italy & $\ldots$ & DAFNE, UT \\
\hline 42 & $\mathrm{~K} 3$ & Y. J. Koh & Psa & A. deliciosa 'Hayward' & Leaf & 1997 & Jeju, Korea & $\ldots$ & DAFNE, UT \\
\hline 43 & Kw30 & NCPPB 3740 & Psa & A. deliciosa 'Hayward' & Leaf & 1984 & Shizuoka, Japan & $\ldots$ & DAFNE, UT \\
\hline 44 & 349 & Balestra & Psa & A. deliciosa 'Summer' & Leaf & 2010 & Portugal & $\ldots$ & DAFNE, UT \\
\hline 45 & 3039B & A. Calzolari & Pss & A. chinensis & Leaf & 2009 & Romagna, Italy & $\ldots$ & DAFNE, UT \\
\hline 46 & $4254 \mathrm{~A}$ & A. Calzolari & $\mathrm{Pv}$ & A. chinensis & Leaf & 2009 & Romagna, Italy & $\ldots$ & DAFNE, UT \\
\hline 47 & 2598 & NCPPB & Pst & Thea sinensis & Leaf & 1970 & Japan & $\ldots$ & DAFNE, UT \\
\hline 48 & Psa92 & Balestra & Psa & A. deliciosa 'Hayward' & Leaf & 1992 & Latina, Italy & $\ldots$ & DAFNE, UT \\
\hline 49 & 827 & Balestra & Psa & A. chinensis 'Jintao' & Leaf & 2011 & Galicia, Spain & $\ldots$ & DAFNE, UT \\
\hline 50 & 830 & Balestra & Psa & A. chinensis 'Jintao' & Leaf & 2011 & Galicia, Spain & $\ldots$ & DAFNE, UT \\
\hline 51 & 18804 & ICMP & Psa & A. chinensis & Leaf & 2010 & New Zealand & $\ldots$ & DAFNE, UT \\
\hline 52 & 18839 & ICMP & Psa & A. deliciosa 'Hayward' & Leaf & 2011 & New Zealand & $\ldots$ & DAFNE, UT \\
\hline 53 & $1 \mathrm{~F}$ & Anses & Psa & A. chinensis 'Jintao' & Leaf & 2010 & Aquitaine, France & $\ldots$ & DAFNE, UT \\
\hline 54 & $2 \mathrm{~F}$ & Anses & Psa & A. deliciosa 'Hayward' & Leaf & 2010 & Rhone Alpes, France & $\ldots$ & DAFNE, UT \\
\hline
\end{tabular}

a Species or pathovar: $\mathrm{Psa}=$ Pseudomonas syringae pv. actinidiae, Pss $=P$. syringae pv. syringae, Pst $=P$. syringae pv. theae, and Pv $=P$. viridiflava.

b Isolation tissue.

c Isolation year.

d DAFNE = Department of Science and Technologies for Agriculture, Forestry, Nature and Energy. 
sequencer according to the manufacturer's instructions. The sequences obtained from the housekeeping genes were submitted to the NCBI database for homologous alignment analysis (Table 3). The phylogenic trees were constructed using the Molecular Evolutionary Genetics Analysis (MEGA) software MEGA 6.0 (Tamura et al. 2013) based on the minimum-evolution method with the nucleotide sequences to infer the genetic relationships between the tested strains of $P$. syringae pv. actinidiae and some known strains in the NCBI database: MAFF 212054, MAFF 212055, and MAFF 212056 (all biovar 5); 212130, 212132, and 212134 (all biovar 6); NCPPB 3739, NCPPB 3871, MAFF 302145, and MAFF 302143 (all biovar 1) from Japan and NCPPB 3873 from Italy (biovar 1); KACC 10584, KACC 10754, and KACC 10594 from Korea (all biovar 2); CRA-FRU 10.22 from Italy, Psa1A and Psa1B from Chile, T11-0918, T10-04782, and T10-05454 from New Zealand (all biovar 3); T11-01369A from Australia and T10-05195, T10-05163, and T10-04976 from New Zealand (all biovar 4, $P$. syringae pv. actinidifoliorum) were used as the positive controls for each biovar.

Detection of phytotoxin and effector genes. Presence of phytotoxin gene clusters (the $\operatorname{tox}$ - $\arg K$ gene cluster coding for phaseolotoxin and the $c f l$ gene coding for coronatine) was performed for all 51 strains of $P$. syringae pv. actinidiae described above and was checked by PCR amplification, which was performed as described in previous studies (Bereswill et al. 1994; Sawada et al. 2002). The presence of 11 effector genes (hopAl, hopH1, hopAF1, hopAA1-1, hopAA1-2, avrD1, hopB1, hopD1, hopAM1, hopAHl, and hopXl) was checked for by PCR

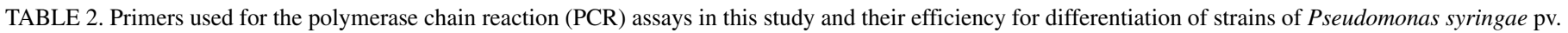
actinidiae infecting kiwifruit

\begin{tabular}{|c|c|c|c|c|c|c|}
\hline $\begin{array}{l}\text { Method, } \\
\text { primer }^{\mathrm{a}}\end{array}$ & Sequence & References & $\begin{array}{c}\text { Annealing } \\
\text { temperature }\left({ }^{\circ} \mathrm{C}\right)^{\mathrm{b}}\end{array}$ & $\begin{array}{c}\text { Total } \\
\text { bands } \\
\text { amplified }^{\mathrm{b}}\end{array}$ & $\begin{array}{l}\text { Polymorphic } \\
\text { bands }\end{array}$ & $\begin{array}{l}\text { Differential } \\
\text { bands }(\%)^{\mathrm{c}}\end{array}$ \\
\hline \multicolumn{7}{|l|}{ Rep-PCR } \\
\hline ERIC1R & 5'ATGTAAGCTCCTGGGGATTCA-3' & $\begin{array}{l}\text { Weingart and } \\
\text { Volksch } 1997\end{array}$ & 52 & 11 & 4 & 63.6 \\
\hline ERIC2 & 5'-AAGTAAGTGACTGGGGTGAGCG-3' & $\ldots$ & & & & \\
\hline BOXA1R & 5'-CTACGGCAAGGCGACGCTGACG-3' & $\ldots$ & 53 & 10 & 5 & 50.0 \\
\hline (GTG) 5 & 5'-GTGGTGGTGGTGGTG-3' & $\ldots$ & 45 & 11 & 8 & 27.3 \\
\hline \multicolumn{7}{|l|}{ RAPD-PCR } \\
\hline OPA-13 & $5^{\prime}-\mathrm{CAGCACCCAC-3^{ \prime }}$ & $\begin{array}{l}\text { Mazzaglia } \\
\text { et al. } 2011\end{array}$ & 45 & 10 & 3 & 70.0 \\
\hline A-24 & 5'-CTCCTGCTGTTG-3' & $\ldots$ & 45 & 9 & 7 & 22.2 \\
\hline A-29 & 5'-GGTTCGGGAATG-3' & $\ldots$ & 45 & 18 & 0 & 100 \\
\hline A-44 & 5'-GACGGTTCAAGC-3' & $\ldots$ & 41 & 14 & 0 & 100 \\
\hline $\mathrm{C}-24$ & 5'-CCTTGGCATCGG-3' & $\ldots$ & 45 & 8 & 3 & 62.5 \\
\hline C-44 & $5^{\prime}-\mathrm{CGCAGCCGAGAT-3^{ \prime }}$ & $\ldots$ & 45 & 13 & 3 & 76.9 \\
\hline OLD-F & 5'-CACGATACATGGGCTTATGC-3' & $\ldots$ & 45 & 14 & 1 & 92.9 \\
\hline OLD-R & 5'-CTTTTCATCCACACACTCCG-3' & $\ldots$ & 45 & 13 & 1 & 92.3 \\
\hline \multicolumn{7}{|l|}{ IS50-PCR } \\
\hline IS50 & 5'-GGTTCCGTTCAGGACGCTAC-3' & $\begin{array}{l}\text { Weingart and } \\
\text { Volksch } 1997\end{array}$ & 45 & 14 & 10 & 28.6 \\
\hline
\end{tabular}

a ERIC = enterobacterial repetitive intergenic consensus, RAPD = random amplified polymorphic DNA, and IS50 = insertion sequences 50.

b Total and polymorphic bands amplified for each primer refer to only the 51 strains of Pseudomonas syringae pv. actinidiae.

c Percentages of the differential bands $=[$ (total bands - polymorphic bands $) /$ total bands $] \times 100 \%$.

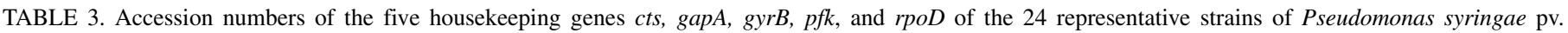
actinidiae used in this study and deposited in the GenBank database of the National Center for Biotechnology Information

\begin{tabular}{|c|c|c|c|c|c|c|}
\hline Number & Strain & cts & gapA & gyrB & $p f k$ & rpoD \\
\hline 1 & Schy9 & KM896669 & KP297246 & KP297265 & KP297284 & KP297303 \\
\hline 2 & GC31 & KM896670 & KP297247 & KP297266 & KP297285 & KP297304 \\
\hline 3 & SH8 & KM896671 & KP297248 & KP297267 & KP297286 & KP297305 \\
\hline 4 & JF8 & KM896672 & KP297249 & KP297268 & KP297287 & KP297306 \\
\hline 5 & INS & KM896673 & KP297250 & КР297269 & KP297288 & KP297307 \\
\hline 6 & $\mathrm{P} 1$ & KM896674 & KP297251 & KP297270 & KP297289 & KP297308 \\
\hline 7 & Hwd3 & KM896660 & KP297252 & KP297271 & KP297290 & KP297309 \\
\hline 8 & Jzzm2 & KM896661 & KP297253 & KP297272 & KP297291 & KP297310 \\
\hline 9 & Jzhy2 & KM896656 & KP297254 & KP297273 & KP297292 & KP297311 \\
\hline 10 & Jzhy14 & KM896659 & KP297255 & KP297274 & KP297293 & KP297312 \\
\hline 11 & $\mathrm{~K} 3$ & KM896662 & KP297256 & KP297275 & KP297294 & KP297313 \\
\hline 12 & 349 & KM896663 & KP297257 & KP297276 & KP297295 & KP297314 \\
\hline 13 & 830 & KM896665 & KP297258 & KP297277 & KP297296 & KP297315 \\
\hline 14 & 827 & KM896664 & KP297259 & KP297278 & KP297297 & KP297316 \\
\hline 15 & $1 \mathrm{~F}$ & KM896666 & KP297260 & KP297279 & KP297298 & KP297317 \\
\hline 16 & 18804 & KM896668 & KP297261 & KP297280 & KP297299 & KP297318 \\
\hline 17 & Jzhy6 & KM896657 & KP297262 & KP297281 & KP297300 & KP297319 \\
\hline 18 & Jzhy7 & KM896658 & KP297263 & KP297282 & KP297301 & KP297320 \\
\hline 19 & Psa92 & KM896667 & KP297264 & KP297283 & KP297302 & KP297321 \\
\hline 20 & Jzmc1 & KJ855759 & KP100046 & KP100031 & KP100036 & KP100041 \\
\hline 21 & Jzgmc2 & KJ855760 & KP100047 & KP100032 & KP100037 & KP100042 \\
\hline 22 & WT3 & KJ855761 & KP100048 & KP100033 & KP100038 & KP100043 \\
\hline 23 & 7285 & KJ855762 & KP100049 & KP100034 & KP100039 & KP100044 \\
\hline 24 & 18839 & KJ855763 & KP100050 & KP100035 & KP100040 & KP100045 \\
\hline
\end{tabular}


amplification using gDNA of 24 representative strains following the protocol described by Ferrante and Scortichini (2009, 2010, and 2011). Primers were synthesized by the Sengon Co., Ltd. (Table 4). A constellation diagram was constructed based on presence or absence data for the four loci coding phytotoxins and 11 effector genes based on the Ward method using JMP Software for Windows, version Pro 14.

\section{RESULTS}

Strains of $P$. syringae pv. actinidiae from different geographic regions in China. All 269 isolates collected had the biochemical characteristics of $P$. syringae pv. actinidiae; that is, they were not or were only slightly fluorescent on King's B medium, they induced an HR when infiltrated into tobacco plants but did not cause potato rot, they did not produce syringomycin or induce ice nucleation, and they did not have a cytochrome c oxidase or an arginine dehydrolase. They all produced levan.

Unique fragment produced by PCR. Most strains of $P$. syringae pv. actinidiae had a similar fingerprint pattern generated by Rep-PCR using primer BOXA1R, with the exception of the five strains GC31, GC32, GC40, GC41, and GC42 (Supplementary Figure S2) from Guizhou Province, which had a unique fragment of approximately $1,500 \mathrm{bp}$. In addition, strains K3 and Kw30 from Korea and Japan, respectively, possessed a unique fragment of approximately $300 \mathrm{bp}$, and strains K3, Kw30, and Psa92 from Italy lacked a polymorphic fragment of approximately $1,100 \mathrm{bp}$.

The RAPD-PCR primer A-24 produced nine amplicons but the percentage of differential bands was only $22.2 \%$ and there was a distinctive 3,000-bp amplicon that was present only with strain 18804 and a second distinctive 1,800-bp amplicon with strains SH2, SH8, SH13, SH18, and SH26 from Shanghai; strains WT2 and WT3 from Yuexi County; and strains Jzhy2, Jzhy3, and Jzhy6 from Jinzhai County.
According to the amplicon pattern generated by IS50-PCR, the strains of $P$. syringae pv. actinidiae from Asia, including those from China, Korea, and Japan, had a similar pattern which was similar to the amplicon patterns for strains from Portugal and Italy, except for Psa92. However, the strains of $P$. syringae pv. actinidiae from Spain and France had a pattern similar to the strain of $P$. syringae pv. actinidiae with high virulence ( $P$. syringae pv. actinidiae 18839) from New Zealand, and there was a distinctive pattern produced by strain $P$. syringae pv. actinidifoliorum 18804, a low-virulence isolate from New Zealand.

Different PCR components to differentiate populations of $\boldsymbol{P}$. syringae pv. actinidiae. The amplification of the gDNA of the 54 selected bacterial strains (51 strains of $P$. syringae pv. actinidiae), followed by gel electrophoresis of the resulting PCR products, showed that polymorphic amplicons accounted for $34.5 \%$ of the 145 total amplicons assessed.

The percentage of differential bands in Rep-, RAPD-, and IS50PCR was 47.0, 77.1, and $28.6 \%$, respectively. This indicates that RAPD-PCR is the most efficient for the differentiation of populations of $P$. syringae pv. actinidiae but the stability of amplicons produced was not always consistent.

With Rep-PCR, primer ERIC1R-ERIC2, BOXA1R, and (GTG) 5 generated 11, 10, and 11 fragments, respectively, and the percentage of differential bands was $63.6,50.0$, and $27.3 \%$, respectively, which indicated that ERIC1R-ERIC2 would be a more efficient primer for differentiating strains of $P$. syringae pv. actinidiae using Rep-PCR.

Genetic relationship of populations of $P$. syringae pv. actinidiae from China and other countries. In total, 145 discrete amplicons were generated with the 51 bacterial strains tested from eight countries (Japan, South Korea, Italy, France, Portugal, Spain, New Zealand, and China) using the three methods of PCR. The strains could be discriminated into distinct four groups-Psa1 from Japan and Italy; Psa2 from South Korea; Psa3 from Europe, New Zealand,

TABLE 4. Primer sets used in this study to detect effector and phytotoxin genes of Pseudomonas syringae pv. actinidiae

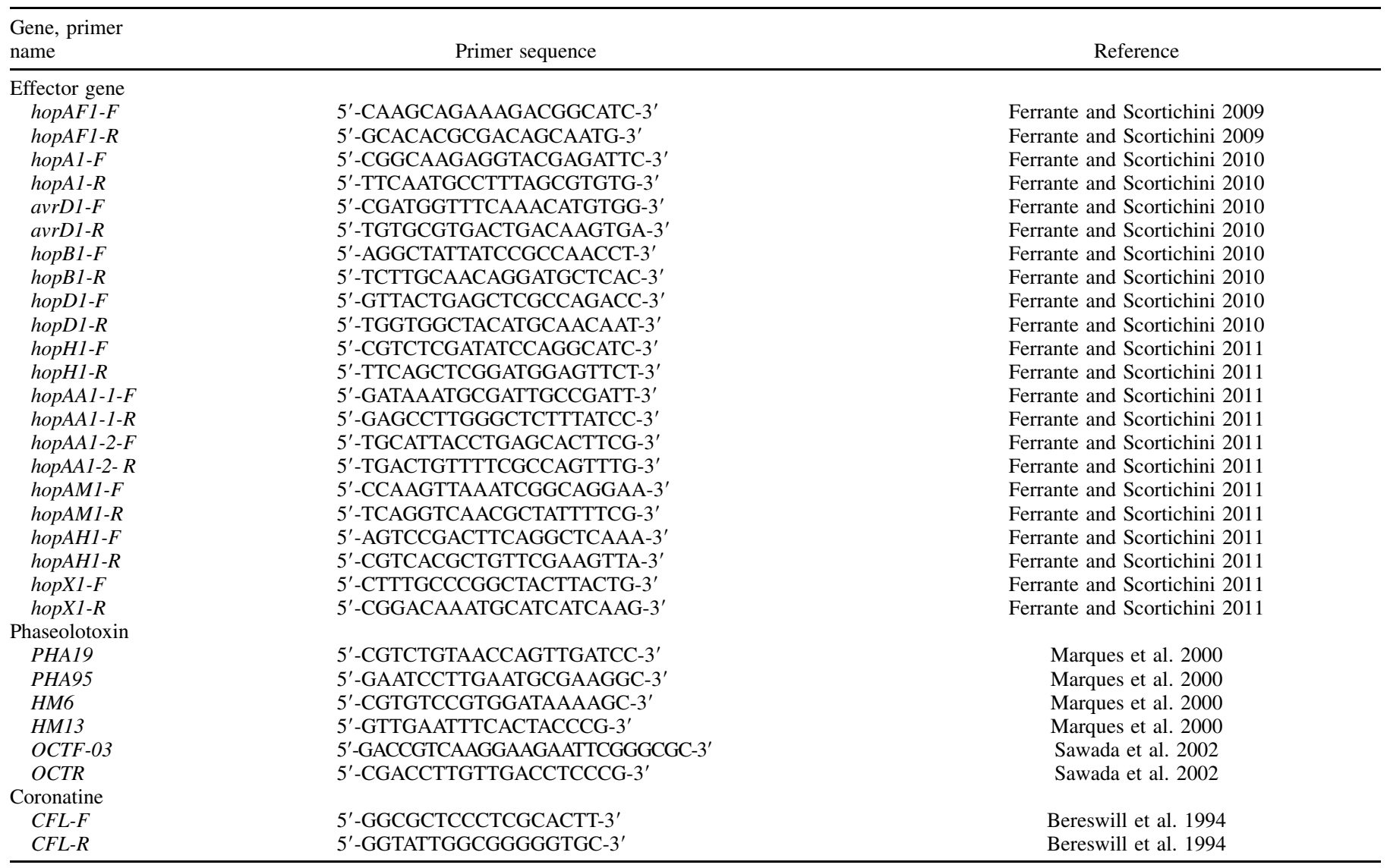


and China; and Psa4 from New Zealand-of which the strains had been reassigned to a new pathovar, $P$. syringae pv. actinidifoliorum. All strains of $P$. syringae pv. actinidiae from China belong to Psa3. The results indicate that strain K3 from South Korea, which was thought to be a member of Psa2, has closer genetic affinity to Psa1 strain Kw30 from Japan (Fig. 1).

PCA revealed that a relatively small portion of the total variance contributed to the first two PCs (PC-1 $=28.1 \%$ and PC-2 $=16.7 \%)$. There were four distinctive subgroups (subgroups 1 to 4 ) in the worldwide group of Psa3 strains; three of the groups came from China (subgroups 1 to 3); strain 349 from Portugal; and strains 7285, 7286, LT19, and LT80 from Italy that were isolated in 2008 and were in the same subgroup 3 as strains from China, implying that they might have the same ancestor. The virulent strain 18839 from New Zealand was in subgroup 4, with strains 827 and 830 from Spain and strains F1 and F2 from France, indicating a close genetic relationship (Fig. 2A).

However, the first four PCs (PC-1 to -4 ) accounted for $68.9 \%$ of the overall variance defining genetic relationships among strains of Psa3 populations worldwide. The plots of PC-1 versus PC-3 or PC-1 versus $\mathrm{PC}-4$ show that strains from China have a broad genetic variability and plots of PC- 2 versus PC- 3 or PC- 2 versus PC- 4 show that the strains from China and strains from Europe and New Zealand have an independent evolutionary direction (Fig. 2B).
Furthermore, the ANOVA showed that significant differences were found for PC-2 and PC-4 but not for PC-1 or PC-3. Strains from China are genetically different from strains from France but are not different from strains from Italy (Supplementary Table S2).

A greater diversity in populations of Psa3 from China was found compared with that previously observed (Cunty et al. 2015a; Liu et al. 2016; McCann et al. 2017). Cluster analysis showed that the strains in clade I were from Xiuwen County in Guizhou Province (GC31-32 and GC40-42); the strains in clade II were from kiwifruit seedling rootstock (JZZM1-2) and two nonkiwifruit species, $S$. viridis (JZMC1-2) and A. philoxeroides (JZGMC1-2); the strains in clade III were primarily from kiwifruit cultivar Hongyang in Jinzhai County, Anhui Province (JZHY2, -3, and -6) and Jiading District in Shanghai municipality (SH2-3, -13, -18, and -28), and from Paulownia tomentosa near a kiwifruit orchard in Yuexi County, Anhui Province (WT2-3); and the strains in clade IV had a wide range of cultivar sources and geographic region origins, including Hongyang kiwifruit in Pengzhou County, Sichuan Province (G3-5, -8, and -12), kiwifruit cultivar Jinfeng (JF8 and J27) and two insect species, Philagra hexamaculata (P1-3) and B. ferruginea (IN5), from an orchard in Yuexi County, Anhui Province, and kiwifruit cultivar Hayward in Huxian County, Shaanxi Province (Hwd1 and -3 to -6 ). These results indicate that each province in China has unique and shared strains; indeed,

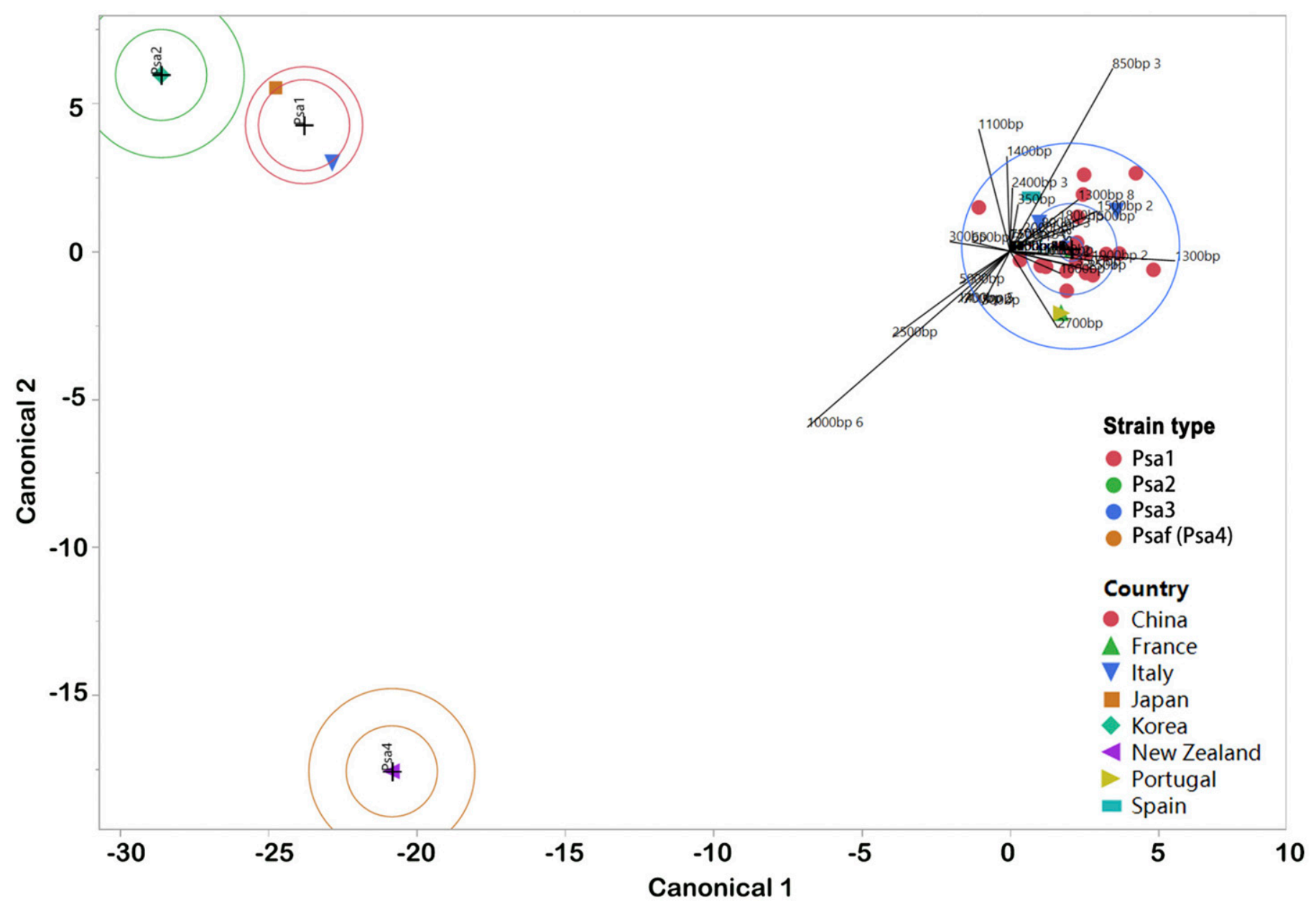

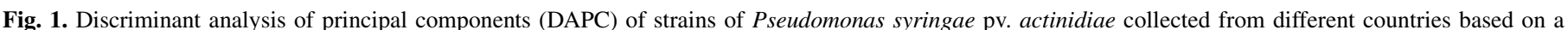

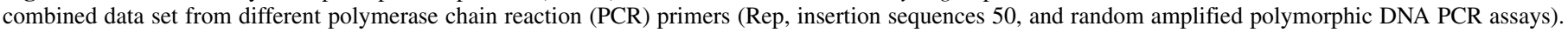

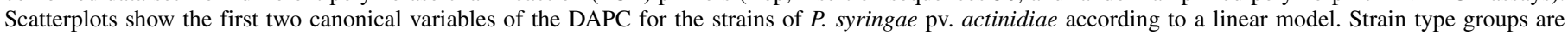

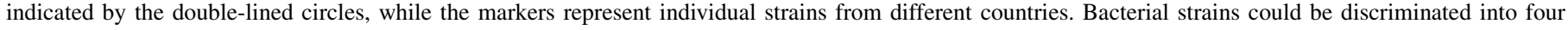

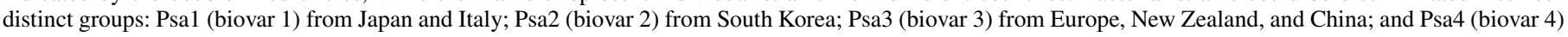

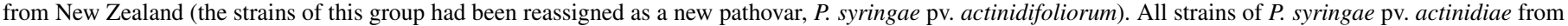
China belong to the Psa3 group. Strain K3 from South Korea has a closer genetic relationship with that of Psa1 from Japan. 
strains from Anhui Province not only had indigenous strains in clade II but also shared strain types with Shanghai Sichuan, and Shaanxi Provinces in clade III and clade IV (Fig. 3).

MLST by housekeeping genes. Sequences of the five housekeeping genes $c t s$, gapA, gyrB, pfk, and rpoD from the 24 representative strains were cloned and submitted to GenBank for homological alignment analysis. All 120 multilocus sequences were analyzed, deposited in the NCBI database, and assigned accession numbers (Table 3 ).

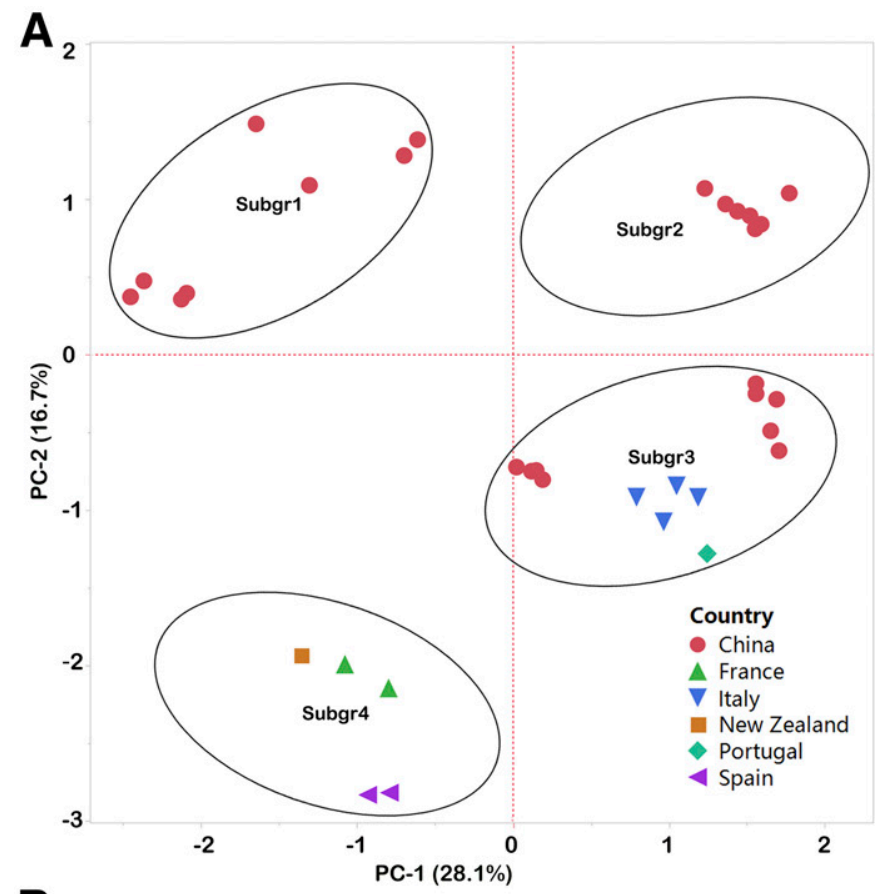

B

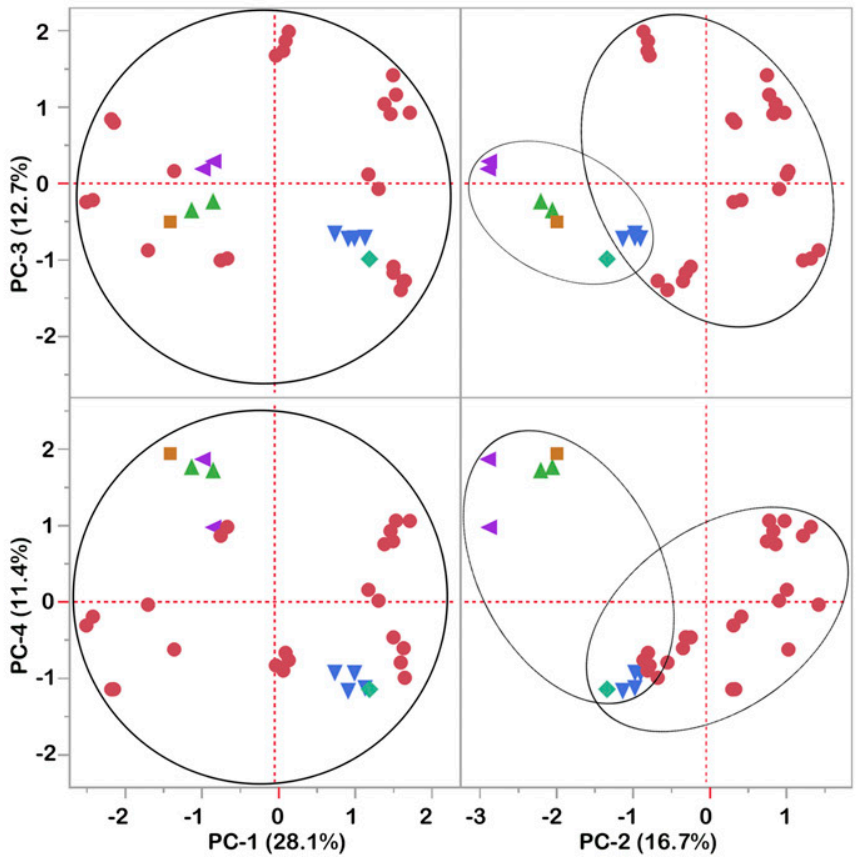

Fig. 2. Principal components analysis (PCA) of strains of Pseudomonas syringae pv. actinidiae collected from different countries based on a combined data set from polymerase chain reaction (PCR) assays using primers for Rep, insertion sequences 50, and random amplified polymorphic DNA PCR assays. Scatterplots show the first two principal components (PCs) of the PCA for the strains of Psa3 according to the covariance model. A, Strain subgroups (Subgr) are shown in different ellipses, with each marker representing individual strains. Strains were discriminated into four subgroups. B, The first two PCs had a relatively small contribution (44.8\%) and the first four PCs accounted for just $68.9 \%$ of the total variance.
The MLST revealed that the genetic variability among the strains of $P$. syringae pv. actinidiae differed from that resulting from the different PCR assays. The phylogenic tree constructed by the combined MLST data showed that the 24 strains of $P$. syringae pv. actinidiae had distinct multilocus sequence profiles but there was clustering of strains from different biovars or MLST groups (biovars 1 to $3, P$. syringae pv. actinidifoliorum, and biovars 5 and 6), compared with the 25 previously characterized strains in the NCBI database used as positive controls for biovar IDs and strain DC3000 of $P$. syringae pv. tomato, which was used as an outgroup.

All of the strains of $P$. syringae pv. actinidiae from China, with the exception of strain Jzhy2, were in the same group as strain 7285 from Italy (cause of the KBC outbreak since 2008); strains 18839, T11-0918, T10-04782, and T10-05454 from New Zealand; strains 827 and 830 from Spain; strain 349 from Portugal; and strain $1 \mathrm{~F}$ from France, all of which were classified as biovar 3 (Psa3). Only strain Jzhy2 from China was differentiated in an independent clade apart from the existing biovars or MLST groups. Interestingly, strains MAFF 212054, MAFF 212055, and MAFF 212056 (newly identified strains from Japan in biovar 5) had a closer genetic relationship to KACC 10584, KACC 10754, and KACC 10594 from Korea, all in biovar 2 (Psa2); and strains in biovar 6 were genetically closer to biovar 1. In contrast, K3 isolated in 1997 from Jeju, Korea clustered with strains Kw30, NCPPB 3739, NCPPB 3871, MAFF 302145, and MAFF 302143 from Japan and Psa92 from Italy and were classified as biovar 1 or Psa1 (Fig. 4).

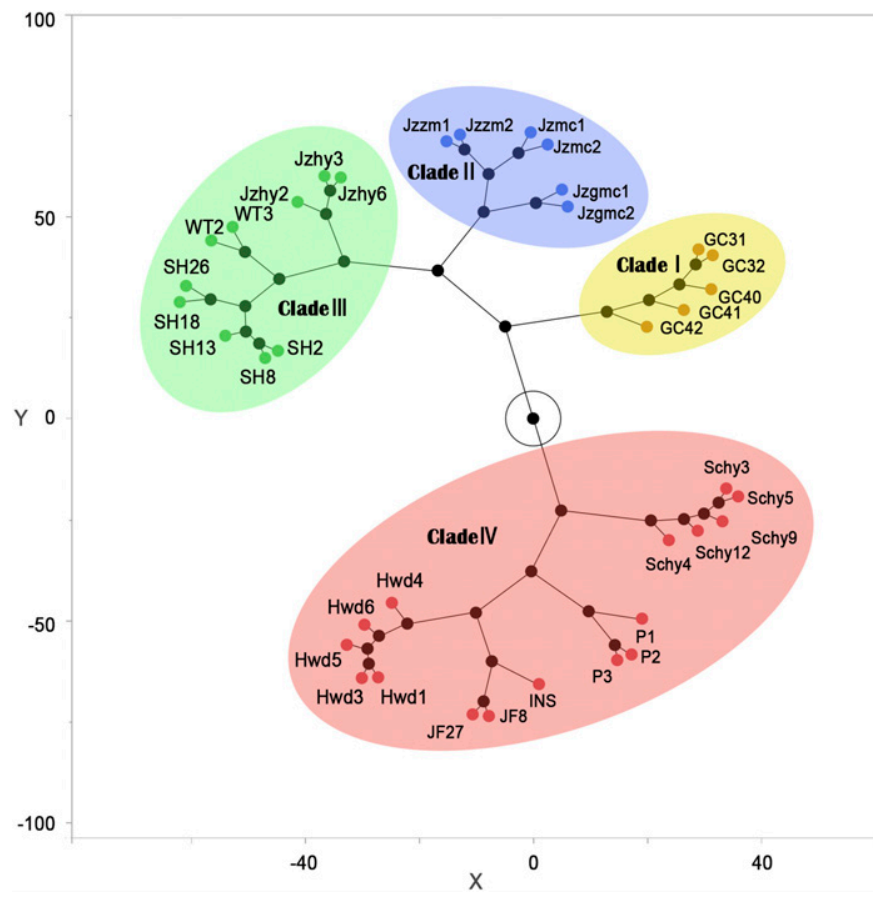

Fig. 3. Constellation plot of strains of Pseudomonas syringae pv. actinidiae from China constructed by hierarchical cluster analysis using combined data from multiple polymerase chain reaction (PCR) fingerprinting with different primers for Rep, insertion sequences 50, and random amplified polymorphic DNA PCR assays. Strains in clade I were from Xiuwen County, Guizhou Province (GC31-32 and GC40-42); strains in clade II were from a seedling rootstock of kiwifruit (JZZM1-2) and two nonkiwifruit species, Setaira viridis (JZMC1-2) and Alternanthera philoxeroides (JZGMC1-2). Strains in clade III were primarily from Hongyang kiwifruit from Jinzhai County, Anhui Province (JZHY2, -3, and -6) and Jiading District in Shanghai municipality (SH2-3, -13, -18 , and -28), and from Paulownia tomentosa growing near a kiwifruit orchard in Yuexi County, Anhui Province (WT2-3). Strains in clade IV had extensive cultivar sources with different geographic regions: from kiwifruit Hongyang in Pengzhou County, Sichuan Province (Schy3 to -5 , -9, and -12); cultivar Jinfeng (JF8 and J27), and two insect species collected in kiwifruit orchards, Philagra hexamaculata (P1-3) and Bothrogonia ferruginea (INS), in Yuexi County, Anhui Province; and kiwifruit cultivar Hayward in Huxian County, Shaanxi Province (Hwd1 and -3 to -6 ). 
Strain 18804 of $P$. syringae pv. actinidifoliorum was clustered with T11-01369A from Australia and T10-05195, T10-05163, and T10-04976 from New Zealand, which had low virulence, and was in a clade distant from all strains in biovars 1 to 3 and biovars 5 and 6 . Strain DC3000 of P. syringae pv. tomato was an outgroup.

Genetic variation in phytotoxin and effector genes. All of the tested strains, including K3 from Jeju, South Korea, lacked the $c f l$ gene coding for coronatine. In contrast, the tox-argK gene cluster coding for phaseolotoxin was detected in strains K3 and Psa92 (Supplementary Table S3). This is the first report that at least some strains of $P$. syringae pv. actinidiae from South Korea have the $\operatorname{tox}$ - $\arg K$ gene cluster coding for phaseolotoxin.

The constellation diagram showed that the strains from China formed two clades (clade 1 and clade 2); the strains from Europe and the virulent strain from New Zealand were in clade 2 . However, the low-virulence strains from New Zealand were in an independent clade (clade 3), strains of which are now considered a new pathovar, P. syringae pv. actinidifoliorum; the biovar 6 strains from Japan were grouped in clade 4, closer to biovar 1; strains K3, Kw30, and Psa92 clustered in clade 5 (biovar 1); the strains from Japan grouped originally in biovar 5 grouped in clade 6 , closer to biovar 2; and those strains in biovar 2 clustered in clade 7 (Fig. 5).

Strains K3, Kw30, and Psa92 in biovar 1 lacked both the amplified 444-bp fragment for effector gene hopAl and the 605-bp fragment for effector gene hopH1. Strain P. syringae pv.

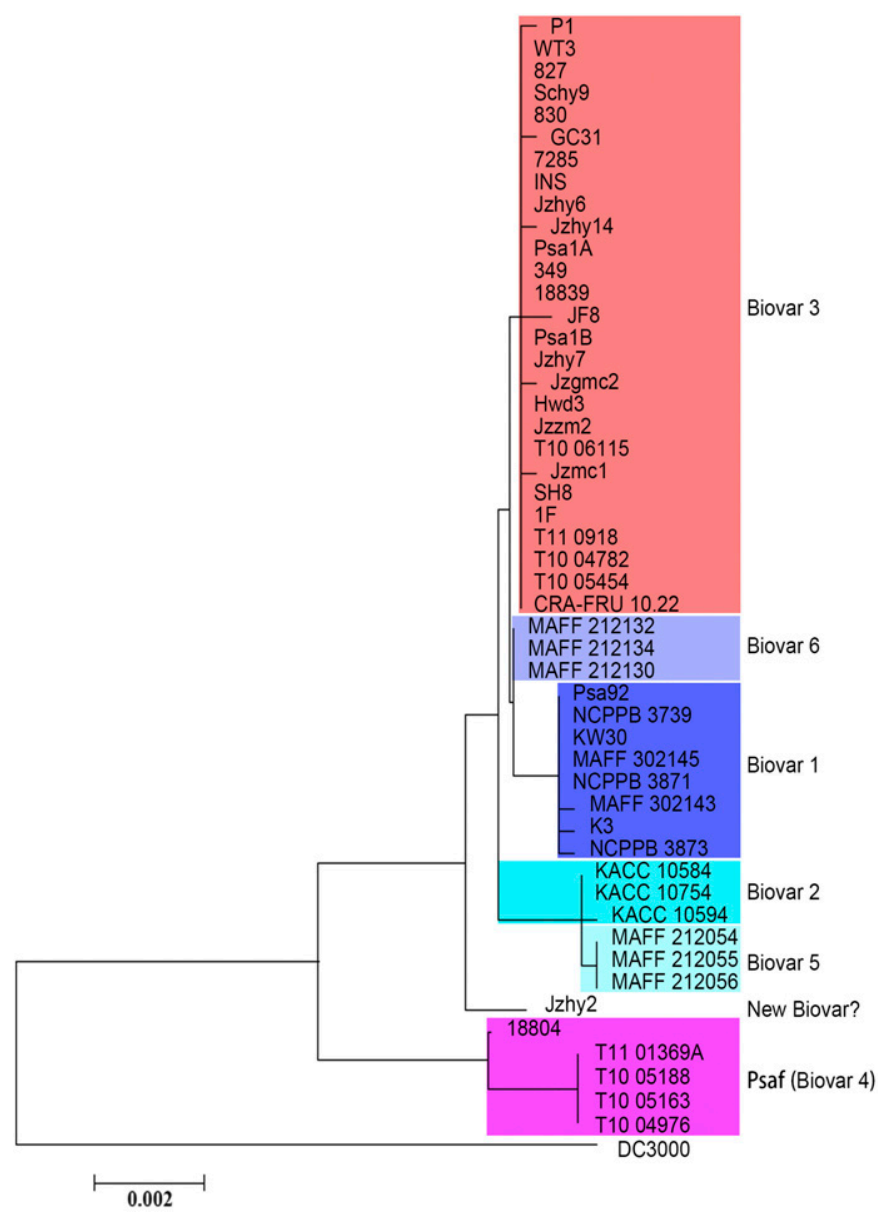

Fig. 4. Phylogenetic tree obtained from the combined sequence data of the five housekeeping genes $c t s$, gapA, gyrB, pfk, and $r p o D$. The phylogenetic tree was constructed using MEGA 6.0 software and the minimum-evolution method. Bootstrap confidence values are indicated at each node and the scale bar indicate the genetic distance. The 25 known strains from the National Center for Biotechnology Information database were used as positive controls for biovar identity, and strain DC3000 of Pseudomonas syringae pv. tomato was used as an outgroup. actinidifoliorum 18804 (former biovar 4) produced an amplicon for hopAl but not for hopHl; and the remaining strains in biovar $3 \mathrm{had}$ amplicons for both hopAl and hopHl genes, except for strains Jzhy2 and Jzhy6, which only produced amplicons for hopH1 but lacked the hopAl gene (Supplementary Fig. S3).

It was notable that, of all the strains (Jzhy1 to -16) yielding an amplicon for hopH1, only five (Jzhy7, Jzhy13, Jzhy14, Jzhy15, and Jzhy16) yielded an amplicon for hopAl. Although the 16 strains were isolated from the same host cultivar (Actinidia chinensis 'Hongyang') in the same orchard (Jinzhai County, Anhui Province, China), 11 strains (Jzhy1 to -6 and Jzhy8 to -12) belonged to a new genotype that differed from the existing biovars or MLST groups according to the combination of the hopAl and hopHl effector genes.

With the exception of strain 18804, a common amplicon was found in the 24 representative strains screened for hopAM1. Sequence analysis showed that strains K3, Kw30, and Psa92 had a longer amplicon $(1,784 \mathrm{bp})$ compared with that produced for the hopAM1 sequence from other strains (701 bp).

\section{DISCUSSION}

PCR assay and MLST. The genetic variability and relationships among the strains of $P$. syringae pv. actinidiae characterized by the PCR assays differed slightly from that characterized by MLST: the PCR was more sensitive compared with the MLST in the discrimination of the $P$. syringae pv. actinidiae populations. According to the results of the PCR assay, the variation among strains of $P$. syringae pv. actinidiae from China was related to the geographic source location. Each of the geographic regions had unique strain variants of $P$. syringae pv. actinidiae; for example, strains in clade I were from Xiuwen County in Guizhou Province,

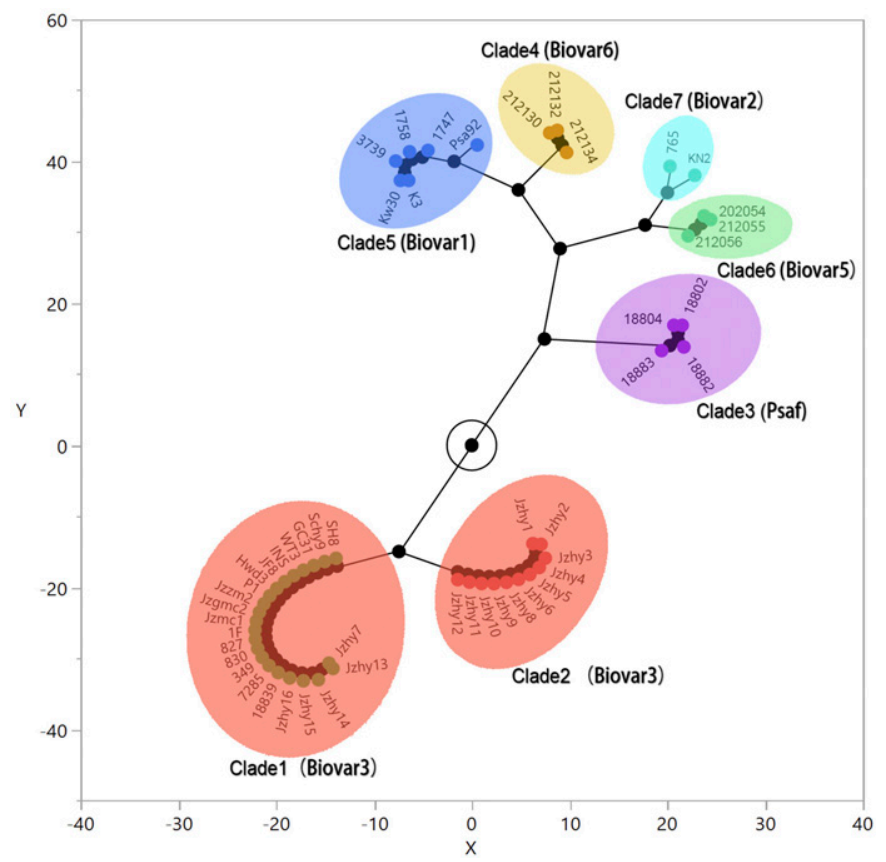

Fig. 5. Constellation plot of strains of Pseudomonas syringae pv. actinidiae from different countries constructed by hierarchical cluster analysis using the amplicon data for four loci coding phytotoxins and 11 effector genes. Note: The strains of $P$. syringae pv. actinidiae from China formed two distinct clades, clade 1 and clade 2, the European strains and virulent strain from New Zealand merged with clade 2; the low-virulence strains from New Zealand are transferred to a new pathovar, clade 3 (P. syringae pv. actinidifoliorum); and the new biovar 6 representing a strain from Japan was grouped in clade 4, closer to biovar 1; strains K3, Kw30, and Psa92 clustered as clade 5 (biovar 1); the remaining strains in biovar 5 from Japan formed clade 6, closer to biovar 2; and strains in biovar 2 clustered in clade 7 . 
clade II from Yuexi County in Anhui Province, clade III mainly from Jiading District in Shanghai, and clade IV mainly from Weixian in Shaanxi Province.

However, in some cases, RAPD-PCR has been reported to lack reproducibility (Tyler et al. 1997). Furthermore, with Rep-PCR, the same reaction performed at different laboratories may result in different profiles for the same or similar strains of $P$. syringae $\mathrm{pv}$. actinidiae (Ferrante and Scortichini 2011; Mazzaglia et al. 2011). In our study, to ensure the reliability of the results, we selected reliable primers, used high-fidelity $T a q$ polymerase, used a precise thermal cycler, and repeated the reactions to confirm reproducibility of amplification.

The RAPD method used in this investigation was able to discriminate strains of $P$. syringae pv. actinidiae at and below the level of biovar, and the discriminating power of this method has been confirmed by others (Bereswill et al. 1994; Koh et al. 2014; Mazzaglia et al. 2011). The RAPD method is widely used due to ease of operation, although reproducibility within and between laboratories has been questionable, perhaps due to the method's dependence on the type of Taq polymerase and thermal cycler used or other unidentified reasons (Van De Zande and Bijlsma 1995). On the other hand, in some situations, RAPDs can be reliable and reproducible. In our study, the method provided reproducible results to explore genetic variability when no sequence data were available for the genome in question.

Genetic diversity of populations of $P$. syringae pv. actinidiae in China. DAPC based on the combined PCR dataset demonstrated that the genetic variability in the populations of $P$. syringae pv. actinidiae from China was related to their geographic origin. Previously, and with the exception of strain Jzhy2 of $P$. syringae pv. actinidiae, only biovar 3 had been found in China (Ciarroni et al. 2015; Cunty et al. 2015a; McCann et al. 2017). Although all of the strains of $P$. syringae pv. actinidiae from China belong to biovar 3 , they have the broadest genetic diversity and can be divided into four distinct lineages (clades I to IV), as described in this study. Some of the $P$. syringae pv. actinidiae strains from China (Jzhy1 to -6 and Jzhy8 to -12) lacked the hopAl and hopHl effector genes. The presence of both of these genes is thought to be unique to strains of P. syringae pv. actinidiae causing epidemics of KBC on A. chinensis and A. deliciosa in Italy (Ferrante and Scortichini 2011) and New Zealand (Vanneste et al. 2013).

Sequence data from the five housekeeping genes uniquely identified strain Jzhy2 as biovar 3. Four of the housekeeping genes (cts, gapA, gyrB, and $p f k$ ) in strain Jzhy2 were identical to the other strains of biovar 3 but the sequence of $r p o D$ in strain Jzhy2 had a 1-base change at five different positions of the locus sequence, resulting in an amino acid sequence change. Currently, we are conducting a genome sequencing approach of strains of $P$. syringae pv. actinidiae representative of the worldwide collection to reveal whether strain Jzhy2 belongs to a novel biovar of $P$. syringae pv. actinidiae.

Wild kiwifruit infected with $P$. syringae pv. actinidiae has not been found in China, except for the one occurrence near the KBCdiseased orchard described in the current study. However, a strain of $P$. syringae pv. actinidiae was isolated from wild growing plants of A. arguta and A. kolomikta in Japan in 1987 to 1988 (Ushiyama et al. 1992). Thus, only one biovar of $P$. syringae pv. actinidiae has been characterized in China (biovar 3), despite China being recognized as a center of diversity and, thus, of origin for most species of kiwifruit (Ferguson and Huang 2007). This result may be irreconcilable with the prevailing expectation that more biovars of $P$. syringae $\mathrm{pv}$. actinidiae should be present in China.

Genetic variation among the global populations of $P$. syringae pv. actinidiae. Environmental variables other than the host can be expected to influence variability of a plant pathogen (Morris et al. 2009), and producing a few cultivars at a high density can enhance the risk of an epidemic or pandemic of KBC caused by a one or a few specific bacterial pathovars (McCann et al. 2013). The genetic variation in $P$. syringae pv. actinidiae makes transport of host material a possible source of novel strains in new areas, and phytosanitary regulation of the species a priority for consideration. Thus, exchange of kiwifruit plant material has resulted in transport of the pathogen and resulting epidemics of KBC in Italy (Balestra et al. 2018) and South Korea (Koh et al. 2014). Furthermore, some strains isolated from orchards in Japan in 1987 and 1988 where streptomycin had been routinely applied were found to be streptomycin resistant (Nakajima et al. 1995), and copper-resistant strains of $P$. syringae pv. actinidiae were isolated from orchards where copperbased bactericides are used to control bacterial canker caused by P. syringae pv. actinidiae in Japan (Nakajima et al. 2002), Italy (Petriccione et al. 2017), and New Zealand (Colombi et al. 2017). Indeed, these issues regarding the variability and adaptability of $P$. syringae pv. actinidiae have raised questions regarding the reliability of long-term strategies to control KBC solely with copper compounds or antibiotics, and have clear ramifications for transport of plant material between kiwifruit production areas.

Diversity can be related to the geographic origin of a pathogen. Analysis of multiple loci variable number of tandem repeats analysis (MLVA) in P. syringae pv. actinidiae showed broad genetic variability but different strains were also retrievable in Japan and Korea (Ciarroni et al. 2015). Compared with strains collected in 2010, results from Rep-PCR and RAPD analysis revealed a high level of variability in the population of $P$. syringae pv. actinidiae collected from northern Italy in 2014. Indeed, at least two biovars (biovar 3 and $P$. syringae pv. actinidifoliorum biovar 4) of $P$. syringae pv. actinidiae had been found in New Zealand (Vanneste et al. 2013), France (Cunty et al. 2015a), and Spain (Abelleira et al. 2015 ); biovars $1,3,5,6$, and $P$. syringae pv. actinidifoliorum (biovar 4) were found in Japan (Sawada et al. 2014; 2015, 2016, 2017); biovars 1, 2, and 3 were found in Korea (Koh et al. 2014; McCann et al. 2017); and biovars 1 and 3 were found in Italy (Ferrante and Scortichini 2015). However, all of the strains of $P$. syringae pv. actinidiae from China were grouped in biovar 3 by MLST, with the exception of strain Jzhy2. The coexistence of many types of $P$. syringae pv. actinidiae in both Japan and Korea suggested that they are the origin and center of diversity of $P$. syringae pv. actinidiae, rather than China (McCann et al. 2017). The identification of new strains in Japan (Sawada et al. 2016, 2017) and Italy (Marcelletti et al. 2011) supports the assertion that variants may continue to emerge and cause local epidemics and, possibly, pandemics (Vanneste 2017). However, all strains from New Zealand share several singlenucleotide polymorphisms that distinguish them from all other strains of $P$. syringae pv. actinidiae. Similarly, all strains of $P$. syringae pv. actinidiae that caused the epidemic in Italy form a distinct clonal group, and those from Chile form a third group (Butler et al. 2013). MLVA and DAPC revealed that strains isolated in Chile, China, and New Zealand are genetically distinct from strains of $P$. syringae pv. actinidiae isolated in France and in Italy, which appear to be closely related at the genetic level (Cunty et al. 2015a). Another MLVA based on 13 variable number tandem repeat loci indicated that strains of $P$. syringae pv. actinidiae from Italy showed very limited diversity, with strains from China having broader genetic variability and those from Japan and Korea being genetically the most heterogeneous group (Ciarroni et al. 2015).

In this study, the strains from Japan (MAFF 212054, MAFF 212055, and MAFF 212056) that were clustered as the novel biovar 5 also clustered with strains of biovar 2 on the phylogenic tree constructed using the combined sequence data of the five housekeeping genes, although the reported strains of biovar 5 had neither the coronatine nor the phaseolotoxin biosynthetic genes conserved in biovar 2 (Sawada et al. 2014). Thus, the strains of biovar 5 causing KBC in Japan were most closely related to biovar 2 according to the average nucleotide identity assay (Fujikawa and Sawada 2016). Strains of biovar 3 also were isolated in Japan but, among 22 strains, 14 possessed Pac_ICE1 and the remaining 8 had no homologs of Pac_ICE1, Pac_ICE2, or Pac_ICE3 (Sawada et al. 
2015). Recently, another novel biovar (biovar 6) of $P$. syringae pv. actinidiae causing $\mathrm{KBC}$ in Japan was found, and that pathogen did not possess hopH1, hopH3, or hopZ5 genes yet produced both phaseolotoxin and coronatine (Sawada et al. 2016).

Moreover, we found that strain K3 from Jeju, Korea (thought to be $P$. syringae pv. actinidiae biovar 2) had the tox-argK gene cluster coding for phaseolotoxin, lacked the $c f l$ gene coding for coronatine, and clustered in biovar 1 with strains from Japan (Kw30, NCPPB 3739, and MAFF 302145) and Italy (Psa92 and NCPPB 3873) based on MLST of housekeeping genes and the phytotoxin and effector genes. This observation supports prior results based on sequenced genomes of $P$. syringae pv. actinidiae that strain K3 from South Korea grouped with the Japanese isolates in biovar 1 (McCann et al. 2017). It should be emphasized that clades 1 to 7 described in this study used presence of phytotoxin and effector genes to discriminate biovars, and strains of biovar 3 clustered in clades 1 and 2, which are different from the pandemic and nonpandemic clades previously proposed by genome sequencing analysis (McCann et al. 2017).

Strains that cluster in the same clade likely have a common origin, and a number of strains from different geographic regions in the same cluster demonstrate that they should have common ancestry. Nevertheless, long-term and long-distance transmission of strains of $P$. syringae pv. actinidiae is due primarily to the introduction of scions, seedling rootstocks, and pollen of kiwifruit. The strain types of $P$. syringae pv. actinidiae present in different continents was not consistent with the geographic locations of Europe, Asia, or Oceania due to the complex routes for transmission of $P$. syringae pv. actinidiae that have resulted in the introduction and reintroduction of the pathogen worldwide where kiwifruit is cultivated. Migration from kiwifruit to nonkiwifruit species or transmission by insects may also have had a profound effect on the observed genetic variation of $P$. syringae pv. actinidiae (Liu et al. 2016).

\section{ACKNOWLEDGMENTS}

We thank Y. Bing (Tangsheng Kiwifruit Company Ltd., Jinzhai County, Anhui, China) and Z. Chao (EF, AHAU, Hefei, China) for their helpful assistance in field sampling, and C. Watkins (Cornell University, Ithaca, NY, USA) for helpful suggestions and language revisions of the article.

\section{LITERATURE CITED}

Abelleira, A., Ares, A., Aguin, O., Peñalver, J., Morente, M. C., López, M. M., Sainz, M. J., and Mansilla, J. P. 2015. Detection and characterization of Pseudomonas syringae pv. actinidifoliorum in kiwifruit in Spain. J. Appl. Microbiol. 119:1659-1671.

Andersen, M. T., Templeton, M. D., Rees-George, J., Vanneste, J. L., Cornish, D. A., Yu, J., Cui, W., Braggins, T. J., Babu, K., Mackay, J. F., and Rikkerink, E. H. A. 2018. Highly specific assays to detect isolates of Pseudomonas syringae pv. actinidiae biovar 3 and Pseudomonas syringae pv. actinidifoliorum directly from plant material. Plant Pathol. 67:1220-1230.

Balestra, G. M., Buriani, G., Cellini, A., Donati, I., Mazzaglia, A., and Spinelli, F. 2018. First report of Pseudomonas syringae pv. actinidiae on kiwifruit pollen from Argentina. Plant Dis. 102:237.

Bereswill, S., Bugert, P., Volksch, B., Ullrich, M., Bender, C. L., and Geider, K. 1994. Identification and relatedness of coronatine-producing Pseudomonas syringae pathovars by PCR analysis and sequence determination of the amplification products. Appl. Environ. Microbiol. 60:2924-2930.

Butler, M. I., Stockwell, P. A., Black, M. A., Day, R. C., Lamont, I. L., and Poulter, R. T. M. 2013. Pseudomonas syringae pv. actinidiae from recent outbreaks of kiwifruit bacterial canker belong to different clones that originated in china. PLoS One 8:e57464.

Ciarroni, S., Gallipoli, L., Taratufolo, M. C., Butler, M. I., Poulter, R. T. M., and Pourcel, C. 2015. Development of a multiple loci variable number of tandem repeats analysis (MLVA) to unravel the intra-pathovar structure of Pseudomonas syringae pv. actinidiae populations worldwide. PLoS One 10:e0135310.

Colombi, E., Straub, C., Kunzel, S., Templeton, M. D., McCann, H. C., and Rainey, P. B. 2017. Evolution of copper resistance in the kiwifruit pathogen Pseudomonas syringae pv. actinidiae through acquisition of integrative conjugative elements and plasmids. Environ. Microbiol. 19:819-832.

Cunty, A., Cesbron, S., Poliakoff, F., Jacques, M.-A., and Manceau, C. 2015a. Origin of the outbreak in France of Pseudomonas syringae pv. actinidiae biovar 3, the causal agent of bacterial canker of kiwifruit, revealed by a multilocus variable-number tandem-repeat analysis. Appl. Environ. Microbiol. 81:6773-6789.

Cunty, A., Poliakoff, F., Rivoal, C., Cesbron, S., Fischer-Le Saux, M., and Lemaire, C. 2015b. Characterization of Pseudomonas syringae pv. actinidiae (Psa) isolated from France and assignment of Psa biovar 4 to a de novo pathovar: Pseudomonas syringae pv. actinidifoliorum pv. nov. Plant Pathol. 64:582-596.

EPPO. 2011. First report of Pseudomonas syringae pv. actinidiae in Australia. EPPO Rep. Serv. 6:2011/130.

Ferguson, A. R., and Huang, H. 2007. Genetic resources of kiwifruit: Domestication and breeding. Pages 1-121 in: Horticultural Reviews, Vol. 33. J. Janick, ed. John Wiley \& Sons, Inc., Hoboken, NJ.

Ferrante, P., and Scortichini, M. 2009. Identification of Pseudomonas syringae pv. actinidiae as causal agent of bacterial canker of yellow kiwifruit (Actinidia chinensis Planchon) in central Italy. J. Phytopathol. 157:768-770.

Ferrante, P., and Scortichini, M. 2010. Molecular and phenotypic features of Pseudomonas syringae pv. actinidiae isolated during recent epidemics of bacterial canker on yellow kiwifruit (Actinidia chinensis) in central Italy. Plant Pathol. 59:954-962.

Ferrante, P., and Scortichini, M. 2011. Molecular and phenotypic variability among Pseudomonas syringae pv. actinidiae and $P$. syringae pv. theae: The genomospecies 8. J. Plant Pathol. 93:659-666.

Ferrante, P., and Scortichini, M. 2015. Redefining the global populations of Pseudomonas syringae pv. actinidiae based on pathogenic, molecular and phenotypic characteristics. Plant Pathol. 64:51-62.

Fujikawa, T., and Sawada, H. 2016. Genome analysis of the kiwifruit canker pathogen Pseudomonas syringae pv. actinidiae biovar 5. Sci. Rep. 6: Article 21399.

Gross, D. C., and DeVay, J. E. 1977. Population dynamics and pathogenesis of Pseudomonas syringae in maize and cowpea in relation to the in vitro production of syringomycin. Phytopathology 67:475-483.

Jombart, T., Sébastien, D., and François, B. 2010. Discriminant analysis of principal components: A new method for the analysis of genetically structured populations. BMC Genet. 11:94

Koh, H. S., Kim, G. H., Lee, Y. S., Koh, Y. J., and Jung, J. S. 2014. Molecular characteristics of Pseudomonas syringae pv. actinidiae strains isolated in Korea and a multiple PCR assay for haplotype differentiation. Plant Pathol. J. 30:96-101.

Koh, Y. J., Cha, B. J., Chung, H. J., and Lee, D. H. 1994. Outbreak and spread of bacterial canker in kiwifruit. Korean J. Plant Pathol. 10:68-72.

Koh, Y. J., and Nou, I. S. 2002. DNA markers for identification of Pseudomonas syringae pv. actinidiae. Mol. Cells 13:309-314.

Lee, J. H., Kim, J. H., Kim, G. H., Jung, J. S., Hur, J.-S., and Koh, Y. J. 2005. Comparative analysis of Korean and Japanese strains of Pseudomonas syringae pv. actinidiae causing bacterial canker of kiwifruit. Plant Pathol. J. 21:119-126.

Lelliot, R. A., Billing, E., and Hayward, A. C. 1966. A determinative scheme for the fluorescent plant pathogenic pseudomonads. J. Appl. Bacteriol. 29:470-489.

Liang, Y. M., Zhang, X. Y., Tian, C. M., Gao, A. Q., and Wang, P. X. 2000. Pathogenic identification of kiwifruit bacterial canker in Shaanxi. J. Northwest For. Univ. 15:37-39 (In Chinese).

Lindow, S. E., Arny, D. C., and Upper, C. D. 1978. Erwinia herbicola: A bacterial ice nucleus active is increasing frost injury to corn. Phytopathology 68:523-527.

Liu, P., Xue, S., He, R., Hu, J., Wang, X., Jia, B., Gallipoli, L., Mazzaglia, A., Balestra, G. M., and Zhu, L. 2016. Pseudomonas syringae pv. actinidiae isolated from non-kiwifruit plant species in China. Eur. J. Plant Pathol. 145: 743-754.

Marcelletti, S., Ferrante, P., Petriccione, M., Firrao, G., and Scortichini, M. 2011. Pseudomonas syringae pv. actinidiae draft genomes comparison reveal strain-specific features involved in adaptation and virulence to Actinidia species. PLoS One 6:e27297.

Marques, A. S. A., Corbiere, R., Gardan, L., Tourte, C., Manceau, C., Taylor, J. D., and Samson, R. 2000. Multiphasic approach for the identification of the different classification levels of Pseudomonas savastanoi pv. phaseolicola. Eur. J. Plant Pathol. 106:715-734.

Mazzaglia, A., Renzi, M., and Balestra, G. M. 2011. Comparison and utilization of different PCR-based approaches for molecular typing of Pseudomonas syringae pv. actinidiae strains from Italy. Can. J. Plant Pathol. 33:8-18.

McCann, H. C., Li, L., Liu, Y., Li, D., Pan, H., Zhong, C., Rikkerink, E. H. A., Templeton, M. D., Straub, C., Colombi, E., Rainey, P. B., and Huang, H. 2017. Origin and evolution of the kiwifruit canker pandemic. Genome Biol. Evol. 9:932-944.

McCann, H. C., Rikkerink, E. H. A., Bertels, F., Fiers, M., and Lu, A. 2013. Genomic analysis of the kiwifruit pathogen Pseudomonas syringae pv. actinidiae provides insight into the origins of an emergent plant disease. PLoS Pathog. 9:e1003503.

Morris, C. E., Bardin, M., Kinkel, L. L., Moury, B., Nicot, P. C., and Sands, D. C. 2009. Expanding the paradigms of plant pathogen life history and 
evolution of parasitic fitness beyond agricultural boundaries. PLoS Pathog. 5:e1000693.

Nakajima, M., Goto, M., and Hibi, T. 2002. Similarity between copper resistance genes from Pseudomonas syringae pv. actinidiae and P. syringae pv. tomato. J. Gen. Plant Pathol. 68:68-74.

Nakajima, M., Yamashita, S., Takikawa, Y., Tsuyumu, S., Hibi, T., and Goto, M. 1995. Similarity of streptomycin resistance gene(s) in Pseudomonas syringae pv. actinidiae with strA and strB of plasmid RSF1010. Ann. Phytopathol. Soc. Jpn. 61:489-492.

Opgenorth, D. C., Lai, M., Sorrell, M., and White, J. B. 1983. Pseudomonas canker of kiwifruit. Plant Dis. 67:1283-1284.

Petriccione, M., Zampella, L., Mastrobuoni, F., and Scortichini, M. 2017. Occurrence of copper-resistant Pseudomonas syringae pv. syringae strains isolated from rain and kiwifruit orchards also infected by P. s. pv. actinidiae. Eur. J. Plant Pathol. 149:953-968.

Rees-George, J., Vanneste, J. L., Cornish, D. A., Pushparajah, I. P. S., Yu, J., Templeton, M. D., and Everett, K. R. 2010. Detection of Pseudomonas syringae pv. actinidiae using polymerase chain reaction (PCR) primers based on the 16S-23S rDNA intertranscribed spacer region and comparison with PCR primers based on other gene regions. Plant Pathol. 59: 453-464.

Sarkar, S., and Guttman, D. S. 2004. Evolution of the core genome of Pseudomonas syringae, a highly clonal, endemic plant pathogen. Appl. Environ. Microbiol. 70:1999-2012.

Sawada, H., Fujikawa, T., Kita, N., Orihara, N., Shinozaki, T., Shimizu, S., Nakaune, R., and Takikawa, Y. 2017. Characteristics of Pseudomonas syringae pv. actinidifoliorum causing bacterial leaf spot of Actinidia spp. in Japan. Jpn. J. Phytopathol. 83:136-150.

Sawada, H., Kanaya, S., Tsuda, M., Suzuki, F., Azegami, K., and Saitou, N. 2002. A phylogenomic study of the OCTase genes in Pseudomonas syringae pathovars: The horizontal transfer of the $\arg K$-tox cluster and the evolutionary history of OCTase gens on their genomes. J. Mol. Evol. 54:437-457.

Sawada, H., Kondo, K., and Nakaune, R. 2016. Novel biovar (biovar 6) of Pseudomonas syringae pv. actinidiae causing bacterial canker of kiwifruit (Actinidia deliciosa) in Japan. Jpn. J. Phytopathol. 82:101-115.
Sawada, H., Miyoshi, T., and Ide, Y. 2014. Novel MLST group (Psa5) of Pseudomonas syringae pv. actinidiae causing bacterial canker of kiwifruit (Actinidia chinensis) in Japan. Jpn. J. Phytopathol. 80:171-184.

Sawada, H., Shimizu, S., Miyoshi, T., Shinozaki, T., Kusumoto, S., Noguchi, M., Naridomi, T., Kikuhara, K., Kansako, M., Fujikawa, T., and Nakaune, R. 2015. Characterization of biovar 3 strains of Pseudomonas syringae pv. actinidiae. isolated in Japan. Jpn. J. Phytopathol. 81:111-126.

Takikawa, Y., Serizawa, S., Ichikawa, T., Tsuyumu, S., and Goto, M. 1989. Pseudomonas syringae pv. actinidiae pv. nov.: The causal bacterium of canker of kiwifruit in Japan. Ann. Phytopathol. Soc. Jpn. 55:437-444.

Tamura, K., Stecher, G., Peterson, D., Filipski, A., and Kumar, S. 2013. MEGA6: Molecular evolutionary genetics analysis version 6.0. Mol. Biol. Evol. 30:2725-2729.

Tyler, K. D., Wang, G., Tyler, S. D., and Johnson, W. M. 1997. Factors affecting reliability and reproducibility of amplification-based DNA fingerprinting of representative bacterial pathogens. J. Clin. Microbiol. 35:339-346.

Ushiyama, K., Kita, N., Suyama, K., Aono, N., Ogawa, J., and Fujii, H. 1992. Bacterial canker disease of wild Actinidia plants as the infection source of outbreak of bacterial canker of kiwifruit caused by Pseudomonas syringae pv. actinidiae. Ann. Phytopathol. Soc. Jpn. 58:426-430.

Van De Zande, L., and Bijlsma, R. 1995. Limitations of the RAPD technique in phylogeny reconstruction in Drosophila. J. Evol. Biol. 8:645-656.

Vanneste, J. L. 2017. The scientific, economic, and social impacts of the New Zealand outbreak of bacterial canker of kiwifruit (Pseudomonas syringae pv. actinidiae). Annu. Rev. Phytopathol. 55:377-399.

Vanneste, J. L., Yu, J., Cornish, D. A., Tanner, D. J., Windner, R., Chapman, J. R., Taylor, R. K., Mackay, J., and Dowlut, S. 2013. Identification, virulence and distribution of two biovars of Pseudomonas syringae pv. actinidiae in New Zealand. Plant Dis. 97:708-719.

Wang, R., Li, Q., He, S., Liu, Y., Wang, M., and Jiang, G. 2018. Modeling and mapping the current and future distribution of Pseudomonas syringae pv. actinidiae under climate change in China. PLoS One 13:e0192153.

Weingart, H., and Volksch, B. 1997. Genetic fingerprinting of Pseudomonas syringae pathovars using ERIC-, REP-, and IS50-PCR. J. Phytopathol. 145: 339-345. 